\title{
ЛЕЙКОЗ КРУПНОГО РОГАТОГО СКОТА - ДИАГНОСТИКА, ОЗДОРОВЛЕНИЕ, АНТРОПОЗООНОЗНЫЙ ПОТЕНЦИАЛ (ИСТОРИЯ ВОПРОСА)
}

\author{
(обзор)
}

\author{
И.М. ДОННИК ${ }^{1}{ }^{凶}$, М.И. ГУЛЮКИН ${ }^{2}$, В.А. БУСОЛ 3 , Л.В. КОВАЛЕНКО 3 , \\ А.М. КОВАЛЕНКО 4
}

В мировом животноводстве среди опухолевых болезней наиболышую опасность представляет лейкоз крупного рогатого скота. С прошлого века это неопластическое заболевание остается актуальным для ветеринарной медицины и, кроме того, возникает все больше вопросов в связи с потенциальной угрозой вируса лейкоза крупного рогатого скота (Bovine leukemia virus, BLV) для человека. Обозначенная проблема дискутируется (Г.Ю. Косовский с соавТ., 2016), что дополнительно стимулирует как фундаментальные исследования патогена и вызываемой им патологии, так и совершенствование приемов диагностики и оздоровления поголовья для повышения обеспечения эффективного молочного скотоводства и ветеринарно-санитарной безопасности продукции. Проблеме распространения вируса в популяции животных, его особенностям, перспективам оздоровления поголовья на основе селекции и вакцин, разрабатываемых в мире, посвящен ряд публикаций (S.G. Hopkins с соавт., 1997; M.A. Juliarena с соавт., 2017). В своем сообщении мы сравнили исторический опыт эрадикации BLV в CCCP, России и за рубежом, дополнительно сосредоточившись на возможной роли этого патогена в возникновении онкологических заболеваний у людей. Основными методами диагностики лейкоза крупного рогатого скота в ветеринарной практике остаются серологические - реакция иммунодиффузии (РИД) в агаровом геле и иммуноферментный анализ (ИФА, ELISA). Для исследования на лейкоз крупного рогатого скота с правилом асептики и антисептики отбирают пробы крови и молока. В публикации G.C. Buehring с соавт. (2019) coобщается об обнаружении провирусной ДНК BLV в лейкоцитах крови у 38 \% пациентов, обследованных методами ПЦР и секвенирования ДНК. При этом антитела IgG к BLV были обнаружены у $32 \%$, IgM - у 58 \% и IgA - у 32 \% обследованных. Накоплен значительный массив данных об изменении обмена веществ у BLV-положительных животных. В частности, у них нарушается метаболизм критической незаменимой кислоты - триптофана, что приводит к накоплению в организме опасных эндогенных метаболитов: 4-8 раз увеличивается в содержание свободного триптофана, индола и антраниловой кислоты, которые откладываются в органах иммунной и кроветворной системы (лимфатические узлы, селезенка, печень), в молочной железе, легких, почках. Установлено, что молоко, полученное от лейкозных животных, отличается от молока здоровых особей по физико-химическим, бактериологическим (лизоцим), технологическим показателям и минеральному составу. Доказано, что выпаивание мышам линии С57 пастеризованного молока и термически обработанного мяса от РИД-положительных коров приводило к изменениям клеточного состава крови у подопытных животных. Анализ доступных данных позволяет сделать однозначный вывод о повышенной опасности для здоровья человека продукции, полученной от инфицированного BLV крупного рогатого скота. Несмотря на отсутствие убедительных доказательств, что BLV патогенен для человека, обеспокоенность по поводу этиологической роли этого вируса в возникновении онкологических заболеваний у людей дополнительно определяет необходимость продолжать исследования по контролю этого распространенного онкогенного ретровируса в скотоводческих хозяйствах и его эрадикации.

Ключевые слова: лейкоз, Bovine leukemia virus, вирус лейкоза крупного рогатого скота, провирусная ДНК, ПЦР-индикация, IgA, IgM, IgG, клетки крови, эндогенные метаболиты, молоко лейкозных животных, вакцинирование, эрадикация.

Лейкоз крупного рогатого скота (энзоотический лейкоз КРС, ЛКРС) - опасное хроническое инфекционное заболевание опухолевой природы $(1,2)$, к возбудителю которого, кроме крупного рогатого скота, восприимчивы другие домашние и дикие жвачные $(3,4)$; при лейкемии КРС лечение неэффективно. К середине 1960-х годов болезнь встречалась на разных континентах в большинстве стран с развитым скотоводством, что сформировало условия для еще более широкого ее распространения, создающего угрозу отрасли $(5,6)$. Распространение лейкоза причиняет значительный экономический ущерб как в племенном, так и в товарном животноводстве, а также в связи с ограничениями торговли скотом и продуктами 
животного происхождения $(7,8)$. Оздоровление неблагополучных по лейкозу хозяйств продолжает оставаться необходимым условием повышения эффективности молочного скотоводства и обеспечения ветеринарно-санитарной безопасности продуктов животноводства $(9,10)$.

В-лимфотропный вирус бычьего лейкоза (Bovine leukemia virus, BLV) - представитель семейства Retroviradae $(11,12)$, как и вирус гепатита C, транскрипты которого выявляются в малигнантных опухолях человека (13). BLV филогенетически связан с вирусом Т-клеточного лейкоза человека 1-го типа (HTLV-1) (12), инфицирующего CD4+ T-клетки.

Общность закономерностей развития неопластических процессов в органах кроветворения человека и крупного рогатого скота обусловила интерес к изучению лейкозной патологии у исследователей не только ветеринарного, но и медицинского, биологического и других профилей $(14,15)$. Дискутируется возможная роль этого патогена в возникновении онкологических заболеваний у людей $(16,17)$, что дополнительно стимулирует как фундаментальные исследования патогена и вызываемой им патологии, так и совершенствование приемов диагностики и оздоровления поголовья.

В своем сообщении мы сравнили исторический опыт и перспективы эрадикации BLV в России и за рубежом и рассмотрели в этой связи зоонозный и возможный антропозоонозный потенциал BLV.

Лейкоз КРС - проявления, диагностика и индикация. ЛКРС впервые описали в 1871 году (18, цит. по 19), но его возбудитель был открыт только в 1969 году, что позволило начать активное изучение свойств патогена и разработку оздоровительных мероприятий $(1,12,20,21)$. Известно, что инфекция BLV может проявляться в разных формах - как бессимптомное вирусоносительство, гуморальный иммунный ответ на антигены вируса, развитие персистентного лимфоцитоза (гематологическая стадия болезни) или лимфосаркомы (опухолевая стадия болезни) (22). При этом гематологические изменения развиваются у 30 \% КР старше 3 лет, а лимфосаркомы внутренних органов - у 0,1-10 \% инфицированных животных (23-25). Можно наблюдать, особенно в начале развития инфекции, ее переход из одной формы в другую. Этим объясняется факт исчезновения и повторного появления признаков инфекции у некоторых особей, а также наличия фаз ремиссии в ходе персистентного лимфоцитоза (26).

В естественных условиях передача BLV происходит в основном горизонтально (с инфицированными лимфоцитами, в том числе через содержащие их биологические секреты) (26). При бессимптомном течении инфекции трансплацентарная передача вируса имеет место в 5-8 \% случаев, у коров с клиническими проявлениями лейкоза - в 10-20 \% случаев. Распространению лейкоза способствует тесный контакт животных и нарушение правил проведения лечебно-профилактических мероприятий. Животные заражаются при энтеральном или парентеральном проникновении в организм лимфоцитов, содержащих BLV. Экспериментально было установлено, что для заражения вирусом лейкоза корове достаточно внутрикожно ввести 2500 инфицированных возбудителем лейкоцитов. Установлено, что для заражения животного достаточно 0,5 мкл крови, инфицированной вирусом лейкоза (27). Нельзя исключить и трансмиссивный механизм передачи возбудителя $(28,29)$.

Стратегия ликвидации лейкоза КРС, применяемая в разных странах, основывается на результатах изучения патогенеза лейкоза, особенностей иммунного ответа у восприимчивых животных и путей передачи возбудителя. В Европе в 1950-е годы впервые была успешно применена методика выявления инфицированных животных по результатам клинических, 
патологоанатомических и гематологических исследований с последующей изоляцией и исключением больных особей из стада (23).

В 1967 году Международное Эпизоотическое Бюро (МЭБ, World Organisation for Animal Health, OIE) рекомендовало проводить диагностику заболевания на основе результатов гематологического исследования с использованием гематологического ключа для определения персистирующего лимфоцитоза. Подсчет соотношения лимфоцитов стал основным диагностическим инструментом в течение ряда лет во всех станах, в том числе в CCCP $(30,31)$.

J.M. Miller и C. Olson (32), исходя из того факта, что на начальных стадиях развития инфекционного процесса клинические признаки ЛКСР отсутствуют, но появляется достаточное количество вирусоспецифических антител, впервые предложили диагностировать ЛКРС в реакции иммунодиффузии (РИД) с детекцией антител против BLV. Этот передовой для своего времени серологический тест, предложенный в качестве базового диагностического подхода в ветеринарной практике, значительно ускорил как профилактические мероприятия, так и эрадикацию лейкоза (33). В настоящее время базовыми тестами для детекции антител против BLV в сыворотке крови и молоке считаются реакция иммунодиффузии (34) и иммуноферментный анализ (ИФА, ELISA) (35). В Европе в хозяйствах по содержанию крупного рогатого скота серологические тесты по выявлению вирусоспецифических антител начали использовать с 1970 года. К 1979 году в животноводческих стадах Дании были полностью отменены гематологические исследования на лейкоз и рекомендовано обязательное применение реакции иммунодиффузии $(36,37)$. Законодательными документами ЕС с 1988 года также предусмотрено использование для диагностики лейкоза иммуноферментного анализа (ИФА) помимо РИД (38). ИФА выявляет вирусоспецифические антитела с низкими титрами как в сыворотке крови, так и в молоке, что не удается детектировать в РИД (39).

Следующий этап развития диагностики ЛКРС - разработка молекулярно-генетического анализа на основе полимеразной цепной реакции (ПЦР) в ее разных вариантах для выявления провирусной ДНК BLV в геномной последовательности у инфицированных лимфоцитов (40-42). ПЦРанализ часто используют для экстренной детекции в клиническом материале уже через 7 сут после инокуляции макроорганизма (особенно телят) возбудителем при сомнительных результатах серологических исследований (43). ПЦР-детекцию используют при анализе семенного материала (44) и молока (45), так как результаты этого теста являются высокоточными.

О пы т иско ре не н ия ле йкоза КРС. Подходы к искоренению ЛКРС в мировой практике представлены различными стратегиями (46). Первая - «проверяй и удаляй» - заключается в выявлении инфицированных животных гематологическими, серологическими или молекулярно-генетическими методами, их немедленном удалении из стада и быстром убое $(23,47)$. Ее применение сыграло важную роль в ликвидации заболевания в нескольких странах Европы (в частности, в Бельгии и Финляндии). В то же время эта стратегия имеет несколько ограничений, среди которых обязательное низкое исходное распространение инфекции и то, что реализация этой стратегии сопровождается очень значительными финансовыми потерями при государственной компенсации за извлечение животных из стада. Такие страны, как США, Канада, Аргентина и Япония, где не применялась финансовая компенсация, не смогли реализовать эту стратегию (46).

Вторая стратегия - «проверяй и разделяй» - менее затратна, поскольку инфицированных животных не выбраковывают, а отделяют от 
животных, свободных от BLV. Выбраковке подвергают только клинически больных животных (48). Эта стратегия оказалась эффективной для существенного снижения распространенности или даже для ликвидации заболевания в большинстве стран мира $(49,50)$.

Стратегия третьего типа - «проверяй и управляй» - не предусматривает замены BLV-инфицированных животных и заключается в принятии мер биобезопасности, минимизации воздействия инфекционного агента на животных и требует минимальных финансовых вложений (46).

Распространение, система диагностики и меры борьбы с лейкозом КРС в СССР и Российской Федерации. Считается, что распространение лейкоза в нашей стране связано с завозом из Германии племенного скота на территории Западной Сибири, Калининградской, Московской, Ленинградской областей в 1940, 1945-1947 годах (51). В СССР изучение ЛКСР и его возбудителя началось в 1961 году во Всесоюзном (ныне Всероссийском) институте экспериментальной ветеринарии им. Я.Ф. Коваленко (ВИЭВ), а также с начала 1960-х годов на Украине в ННЦ «Институт экспериментальной и клинической ветеринарной медицины» и Белоцерковском государственном аграрном университете. Официальная регистрация ЛКРС в Советском Союзе началась с 1965-1966 годов (52). Результатом научных исследований ВИЭВ стали инструктивные и нормативные материалы (1965, 1969, 1984, 1989 годов), регламентирующие меры борьбы с этим инфекционным заболеванием.

Последние 30 лет в России для диагностики лейкозной инфекции используют РИД и ИФА, выявляющие антитела в сыворотках крови и/или молока (молозива) против антигенов BLV. Многими исследователями показана возможность используется ПЦР для ранней диагностики лейкоза $\operatorname{KPC}(53,54)$.

В Советском Союзе с начала 1990-х годов использовалась стратегия ликвидации ЛКРС по принципу «проверяй и разделяй». При разработке систем диагностики, профилактики и оздоровления неблагополучных по ЛКРС хозяйств важную роль сыграли исследования биологических свойств $\mathrm{BLV}$, инфекционного и эпизоотического процессов. Инактивация BLV при нагревании до $56{ }^{\circ} \mathrm{C}$ происходит в течение 15 мин, при 70-74 ${ }^{\circ} \mathrm{C}-$ за 15-17 с, в молоке при 9-15 ${ }^{\circ} \mathrm{C}-$ за 24-48 ч. Активность вируса сохраняется при рН ниже 6,0 , в $0,5 \%$ растворе едкого натрия, 0,5 \% растворах формальдегида и фенола, 2 \% растворе этилового спирта. Воздействие прямых солнечных лучей убивает вирус лейкоза за 4 ч, ультрафиолетовое излучение за 30 мин (10). Важно также учитывать, что для ЛКРС характерны четыре стадии развития: инкубационная - с момента заражения вирусом лейкоза до появления антител к возбудителю; серологическая (бессимптомная инфекция) - от появления антител до обнаружения гематологических изменений; гематологическая - соответствует развитию персистентного лимфоцитоза; опухолевая - проявляется как развитие злокачественных опухолей в тканях кроветворных и других органов $(25,55)$. Одними из главных иммуногенетических факторов устойчивости или восприимчивости к лейкозу крупного рогатого скота служат антигены гистосовместимости, в частности устойчивость животных к лейкозу определяют аллели гена BoLADRB3, кодирующего антигены II класса главного комплекса гистосовместимости КРС (56).

В Российской Федерации с 1997 года лейкоз КРС занимает первое место в структуре инфекционной патологии $(5,11)$. По состоянию на 1 января 2014 года до 10 \% инфицированности стад наблюдали в 53 субъектах 
Российской Федерации, а в Нижегородской области этот показатель превышал 30 \% (57). В 2016 году новые вспышки лейкоза крупного рога были зарегистрированы более чем в 27 областях России. Всего в 2016 году лейкоз зарегистрировали в 68 субъектах Российской Федерации у 58 тыс. гол КРС. Свободны от этого инфекционного заболевания лишь несколько субъектов РФ (10). Было установлено, что снижение среднегодовой молочной продуктивности в неблагополучных по ЛКСР стадах составляет 218 кг на корову по сравнению с благополучными $(57,58)$.

Ретроспективный анализ заболеваемости лейкозом за 2005-2015 годы в Уральском регионе (данные статистической отчетности Департамента ветеринарии Свердловской области) выявил высокую эпизоотическую напряженность по ЛКРС в большей части молочных хозяйств, расположенных в зоне с комбинированным техногенным загрязнением, характерным для этого региона. Также установлено, что в хозяйствах, находящихся в наиболее загрязненных районах Восточно-Уральского радиоактивного следа (ВУРС), частота выявления положительно реагирующих животных составляла 56-76 \%, гематологически больных - 8-14\%, средняя серопозитивность коров по фермам равнялась $20 \%$, доля имеющих характерные гематологические отклонения - 5,7 \% (59). В районах, не подвергавшихся техногенному загрязнению, инфицированность BLV составила около $1 \%$, а животные с гематологическими нарушениями практически отсутствовали. При проведении гематологических исследований коров с положительной РИД по всему региону с комбинированным радиоактивным загрязнением было выявлено в среднем 12 \% больных. На молочно-товарных фермах, расположенных по оси Восточно-Уральского радиоактивного следа, выявили в 1,5-2,0 раза больше животных с персистирующим лимфоцитозом (59). Неблагополучие по лейкозу в районах техногенного и радиоактивного загрязнения в молочных хозяйствах связывают с иммунными нарушениями, которые приводят к быстрому клиническому развитию лейкоза (60).

Проведенный впервые в Советском Союзе гистоморфологический анализ образцов злокачественных опухолей у КРС показал, что из 5243 прижизненных диагнозов ЛКРС 85,0 \% - собственно лейкоз (из которых $82,70 \%$ - лимфолейкоз, 2,07 \% - гемоцитобластоз, 0,23\% - миелолейкоз), $14,7 \%$ - ретикулезы (7,2 \% - ретикулосаркома, 3,4\% - лимфосаркома, $2,1 \%$ - системный ретикулез, $1,52 \%$ - лимфоретикулез и 0,48 \% - лимфогрануломатоз); на долю остальных опухолей приходилось 0,3 \% (61).

Зарубежный опыт эрадикации лейкоза крупного рогатого скота. Украина. После 1990 года на Украине меры по выявлению и контролю лейкоза и борьбы с ним регулируются соответствующим законодательством, с 2007 года регламентировано применение серологических и геномных методов исследований и диагностики. В целом с 1990 года здесь отмечается значительное снижение инфицированности поголовья лейкозом $(62,63)$.

На начальных этапах реализации программы ежегодное выявление новых неблагополучных по лейкозу КРС пунктов указывало на наличие факторов, способствующих поддержанию напряженной эпизоотической ситуации: исследования без учета времени инкубационного периода лейкозной инфекции; ошибки и несвоевременное проведение диагностики; наличие в оздоравливаемых хозяйствах единичных особей, зараженных BLV, которые при передержке в стаде становятся основными источниками возбудителя; наличие условий для передачи возбудителя; человеческий фактор (ненадлежащее исполнение ветеринарных, зоотехнических и организационно-хозяйственных мероприятий, в частности несвоевременная изоляция и сдача на убой инфицированным вирусом 
лейкоза животных). На основании анализа эпизоотологической ситуации к началу 2000-х годов был предложен четкий комплекс противолейкозных мероприятий, включающий постоянный мониторинг каждого молочно-товарного хозяйства; выявление источников возбудителя лейкоза с использованием высокоспецифичных диагностических тестов для обнаружения инфицированных особей на ранних стадиях инфекционного процесса; немедленная (сразу после выявления) изоляция источников возбудителя лейкоза и его ликвидация в течение 10 сут; надежный зоотехнический учет и нумерация животных; адаптация технологических систем перемещения поголовья, содержание, кормление, выращивание телят в соответствии с требованиями оздоровительных ветеринарно-санитарных мероприятий; проведение ветеринарно-зоотехнических мероприятий; широкоформатность и поэтапность мер по ликвидации лейкоза в стадах крупного рогатого скота, что в итоге привело к положительным результатам $(20,63,64)$.

В рамках масштабной системы ветеринарно-зоотехнической профилактики и оздоровления животных от ЛКРС сначала (1988-1990 годы) было обеспечено производство диагностического препарата для раннего выявления лейкоза крупного рогатого скота (на базе НПС «Орион», г. Харьков, Украина) (65). В 1991-1997 годах проводилась интегральная оценка заболеваемости, по результатам реакции иммунодиффузии определяли активных источников BLV, был осуществлен сквозной зоотехнический учет поголовья и созданы условия для немедленной изоляции выявленных больных особей с последующим убоем (не позднее чем через 15 сут), для поддержания численности поголовья было активизировано воспроизводство стад. Третий этап (с 1998 года) включал собственно проведение системных профилактических и оздоровительных мероприятий (с учетом представлений об эпизоотологии, этиопатогенезе, эпизоотическом процессе) с использованием современных методов прижизненной диагностики $(33,63,66,67)$.

Результативность разработанной ветеринарно-зоотехнической системы оценивается по показателям напряженности эпизоотического процесса по лейкозу, превалентности вируса (степень инфицированности поголовья), инцидентности (частота выявления новых случаев инфекции) и наличию неблагополучных по лейкозу КРС пунктов. Согласно данным ветеринарной статистики, за 17-летний период (1997-2014 годы) превалентность заболевания КРС лейкозом на Украине снизилась в 369 раз, а инцидентность - в 376 раз, частота выявления неблагополучных пунктов - в 745 раз. В результате к 2013-2014 году регистрировали переход эпизоотии в состояние спорадии (63); внедрение разработанной ветеринарно-зоотехнической системы противолейкозных мероприятий здесь в целом признается результативным $(63,68)$. Некоторые исследователи полагают, что полное искоренение ЛКРС возможно только при помощи выявления инфицированных животных без специфической профилактики. Однако это довольно затруднительно, так как идентифицировать всех особей, у которых началась репликация вируса, в самые первые дни после его инокуляции в макроорганизм на сегодняшний день невозможно (15).

Pеспублика Беларусь. В Республике Беларусь в 1990-х годах инфекция BLV была зарегистрирована в 97,8 \% хозяйств и заболевание приобрело характер эпизоотии (68). Активные противолейкозные мероприятия $(69,70)$ снизили долю РИД-положительных животных с 19,6 до 2,4 \% в дойном стаде, с 7,4 до 3,2 \% - среди молодняка и позволили оздоровить 397 неблагополучных хозяйств. К 2011 году доля серопозитивных животных снизилась до $0,1 \%$ (68).

Республика Казахстан. Здесь объем иммунологических иссле- 
дований (РИД, ИФА) крупного рогатого скота на лейкоз в 2002-2011 годах варьировал от 2,3 до 43,7 \%, а процент инфицированности равнялся 3,3\% (колебание от 2,2 в 2009 году до 11,0 \% в 2005 году) (71). Мерам борьбы с этим заболевание здесь уделяется постоянное внимание (72-74) с учетом значимости проблемы для скотоводства Казахстана (71).

Страны Западной и Восточной Европы, Азии, Африки и Амер ики. Примером удачного осуществления национальных программ контроля и ликвидации ЛКРС на основе серологического тестирования крови и молока животных может служить Великобритания. Первая вспышка заболевания здесь была зарегистрирована в 1978 году, последний случай - в 1996 году, и с 1999 года Великобритания официально признана свободной от ЛКРС $(68,75-77)$. Принятая в Великобритании стратегия борьбы с заболеванием предполагает поддержание существующего статуса на основе постоянно выполняемых серологических исследований проб крови и молока и импорта скота исключительно из стран Северной Европы, свободных от лейкоза (68).

По данным МЭБ, в список стран, свободных от лейкоза, также входят Андорра (с 1994 года), Кипр (с 1995 года), Чехия (с 2010 года), Дания (с 1990 года), Египет (с 1997 года), Эстония (с 2013 года), Финляндия (с 2008 года), Грузия (с 1996 года), Ирландия (с 1999 года), Кыргызстан (с 2008 года), Новая Зеландия (с 2008 года), Норвегия (с 2002 года), Словения (с 2006 года), Южная Африка (с 2012 года), Испания (с 1994 года), Швеция (с 2007 года), Швейцария (с 2005 года), Тунис (с 2005 года), Польша (с 2017 года) (указаны годы ликвидации заболевания). В Италии, Португалии, Латвии, Греции, Румынии и Болгарии BLV либо персистирует с незначительными проявлениями, либо заболевание встречается спорадически (68). В странах Северной и Южной Америки, Африки и Азии, а также в Австралии, несмотря на проводимые там противолейкозные мероприятия, в целом сохраняется высокая инфицированности поголовья вирусом ЛКРС (68).

При этом следует отметить, что каждая из стран имеет собственный план по борьбе с лейкозом. К примеру, в США отсутствуют федеральные правила, которые бы ограничивали распространение вируса бычьего лейкоза в популяции КРС, также не предусмотрена обязательная фиксация заражения вирусом лейкоза КРС, и это вызывает большие затруднения в оценке проблемы (68). Так, в 2007 году при исследовании в ИФА сборных проб молока серопозитивность выявлена в среднем у 83,9 \% обследованных стад, а в крупных стадах (более 500 гол.) показатель инфицированности достигал $100 \%$ (68). На 38,0 \% ферм мясного направления продуктивности также отмечали серопревалентность по ВЛКРС (68). По данным на 2018 год, при исследовании проб молока методом ИФА BLV-специфические антитела были обнаружены в среднем в 46,5 \% проб (78). При этом показатель увеличивался с 29,7 \% у коров 1-й лактации до 58,9 \% у коров 4-й лактации и выше (78).

По имеющимся данным, после 2000 года в Канаде до 37,2 \% коров и 89,0 \% стад были BLV-позитивными (79, 80-82). Лейкозная инфекция также широко распространена в Китае и Японии - в некоторых стадах молочного скота серопревалентность достигает соответственно 49,1 и 40,9 \% (82). В то же время менее $6 \%$ крупного рогатого скота были инфицированы в Монголии (3,9\%) и Камбодже $(5,3 \%)(82)$.

Необходимо отметить, что статус зон (государств) и стад, свободных от ЛКРС, определяют санитарные требования при международной торговле животными и животноводческой продукцией, изложенные в утвержденном МЭБ «Санитарном кодексе наземных животных» (83). К таким относятся 
территории, где в течении 3 лет 99,8 \% стад свободны от ЛКРС, а также ведется контроль патологического материала, отобранного от животных с подозрением на лимфосаркому. Чтобы поддерживать статус свободной от лейкоза территории, проводят ежегодные серологические мониторинги, охватывающие до 99 \% поголовья, также обязательны к выполнению все требования к импортируемому скоту и генетическим ресурсам.

Зоонозный и возможный антропозоонозный потенциал BLV. Функциональное и структурное сходство BLV с вирусами возбудителями Т-клеточного лейкоза человека (HTLV-I, HTLV-II) и Т-лимфотропными вирусами обезьян, для которых свойственно преодолевать видовой барьер и при экспериментальных условиях провоцировать инфекционный процесс у овец $(84,85)$, кроликов, свиней и обезьян $(29,86,87)$, обусловливает важное социальное значение лейкоза (88). В одной из наиболее ранних и часто цитируемых работ Н.M. McClure и соавт. (87) описано возникновение эритролейкемии и пневмонии (возбудитель Pneumocystis carinii) у двух из шести младенцев шимпанзе, которые с рождения питались непастеризованным молоком от коров, зараженных BLV естественным путем. Шимпанзе умерли в возрасте 34 и 45 нед после болезни, которая длилась от 5 до 6 нед и характеризовалась вялостью, анорексией, лейкоцитозом, анемией и прогрессирующей пневмонией. В костном мозге и периферической крови погибших животных были обнаружены бластные и незрелые миелоидные клетки (87).

Заслуживают внимания результаты исследований советских ученых, полученные в начале 1970-х годов, о развитии неопластического процесса у телят, экспериментально зараженных кровью больного лейкозом человека. Было доказано наличие в органах больных лейкозом людей и животных общих антигенных детерминант (26).

В 1981 году, анализируя накопленные к тому времени в мировой науке данные, M.J. Burridge (38) делает вывод, что нет никаких результатов эпидемиологических или серологических исследований, которые указывали бы на то, что BLV может заразить человека.

Эти исследования были продолжены, поскольку тот факт, что инфицированные BLV клетки присутствуют в молоке большинства коров, зараженных естественным путем, указывает на то, что люди часто подвергаются воздействию этого возбудителя при его поступлении в организм перорально. Доказана межвидовая передача ВЛКРС, заражающего организм гетерологичного вида животных (кроликов) (29) при поступлении непосредственно в кровяное русло или через желудочно-кишечный тракт, что подтверждает инфекционные свойства молока больных лейкозом коров и свидетельствует о потенциальной опасности употребления парного молока людьми. На основе молекулярно-генетических методов установлено наличие в сыром молоке и говядине гена gag ВЛКРС в 49 \% образцов, которые оказались положительными (15). Это первое исследование, в котором подчеркивается присутствие этого гена в мясных продуктах, потребляемых человеком, и подтверждается наличие вирусной ДНК в сыром молоке. Поскольку пастеризация молока полностью инактивирует BLV, возможность инфицирования человека через молоко нужно изучать с привлечением прежде всего животноводов, работающих с неблагополучными по лейкозу коровами и употребляющих непастеризованное молоко $(38,89,90)$.

Обширные эпидемиологические исследования, проведенные в конце XX-начале XXI века в США, Дании и Швеции, не смогли продемонстрировать связь между лейкозом человека и лейкозом крупного рогатого скота. 
При серологических исследованиях также не обнаружены антитела против BLV у людей с различным возможным воздействием возбудителя (38).

Отсутствие BLV-специфических последовательностей в 157 случаях остро протекающего лимфобластного лейкоза у детей с наличием лимфомы (США) (91) и в 517 случаях лейкемии у человека и 162 пациентов с раком легкого (Корея) (92) послужило дополнительным доказательством того, что BLV не играет роль этиологического фактора при заболевании человека гемобластозами.

Обеспокоенность по поводу возможности заражения человека BLV вновь возникла из-за результатов исследований G.C. Buehring с соавт. (93), которые обнаружили реактивность к белку р24 BLV в 74 \% исследованных человеческих сывороток. Авторы утверждали, что серологические методы, использованные в первоначальных исследованиях, не были достаточно чувствительными для выявления BLV-специфических антител у людей. Хотя менее $10 \%$ человек со специфическими антителами заявляют о прямом контакте с коровами или их биологическими продуктами, авторы приходят к выводу, что антитела у людей могли возникать в ответ на пероральное воздействие денатурированного теплом вируса в продуктах или быть следствием прямого инфицирования человека этим возбудителем (93). Также было установлено, что сыворотки от людей, инфицированных HTLV-1 и HTLV-2, перекрестно реагируют с р24 BLV из-за общего эпитопа (37).

Еще одним доказательством возможной передачи возбудителя BLV от крупного рогатого скота человеку было обнаружение последовательностей вируса с помощью ПЦР в 44 \% образцов тканей молочной железы. Наиболее поразительным открытием было выявление экспрессии р24 BLV иммуногистохимическим методом в секреторном эпителии молочной железы (89). Анализ показал, что число последовательностей BLV в образцах от пациентов с раком молочной железы в 2 раза выше, чем в нормальных срезах тканей молочной железы. Авторы пришли к выводу, что присутствие BLV в тканях молочной железы было связано с раком этого органа (89). Ретротранскрибированная ДНК BLV была обнаружена у 40 из 50 (80\%) женщин с раком молочной железы. При сравнении парных образцов тканей молочной железы от пациенток, у которых первый образец был диагностирован как доброкачественный, а второй - как злокачественный, отобранных с интервалом 3-10 лет, BLV присутствовал у 74 \% женщин уже в доброкачественной ткани молочной железы при первом исследовании (89). Это согласуется с предположением о причинно-временной взаимосвязи между инфекцией BLV и последующим развитием рака. Также отмечается, что доля женщин, имеющих провирусную ДНК BLV в молочной железе и не имеющих в анамнезе рака, составляет $41 \%$ (89).

В вышедших публикациях G.C. Buehring с соавторами сообщается об обнаружении провирусной ДНК BLV в человеческих лейкоцитах: у 38 \% обследованных методами ПЦР и секвенирования геномной провирусной ДНК. При этом антитела IgG к ВЛКРС были обнаружены у 32 \%, IgM у $58 \%$ и IgA - у $32 \%$ обследованных (90). В то же время есть сообщения, что антитела к BLV и его геномные последовательности не обнаруживаются у здоровых женщин и у женщин с раком молочной железы $(16,94)$. Исследования более чем 3700 злокачественных опухолей человека, включая 810 аденокарцином молочной железы, с использованием RNA-сиквенсов не подтвердили предыдущие данные об экспрессии BLV в ткани молочной железы (13).

Продукты, полученные от инфицированных BLV живот ных. Накоплен значительный массив данных об изменении обмена веществ 
у животных, инфицированных BLV. Так, при инфекции происходит нарушение метаболизма критической незаменимой кислоты - триптофана, что приводит к накоплению в организме опасных эндогенных метаболитов: увеличивается в 4-8 раз содержание свободного триптофана, индола и антраниловой кислоты, которые откладываются в органах иммунной и кроветворной системы (лимфатические узлы, селезенка, печень), молочной железе, легких, почках $(68,95)$. Установлено, что молоко, полученное от лейкозных животных, отличается от молока здоровых животных по физикохимическим, бактериологическим (лизоцим), технологическим показателям и минеральному составу. Выпаивание мышам линии С57 пастеризованного молока и термически обработанного мяса РИД-положительных коров приводило к изменениям клеточного состава крови у подопытных животных (96). Мясо и продукты убоя от инфицированных BLV животных по результатам ветеринарно-санитарной экспертизы относят к условно-пригодному сырью, что требует специальной обработки сырья и контроля ветеринарной службой для обеспечения биобезопасности продукции животноводства, производимой в современных условиях $(27,68,97,98)$.

Итак, энзоотический лейкоз крупного рогатого скота (ЛКРС) опасное хроническое инфекционное заболевание опухолевой природы, вызываемое вирусом бычьего лейкоза (Bovine leukemia virus, BLV) - представителем семейства Retroviradae. Несмотря на то, что многие страны официально признаны свободными от ЛКРС, проблема его эрадикации не решена. Анализ доступных данных позволяет сделать однозначный вывод о повышенной опасности продукции, полученной от инфицированного BLV крупного рогатого скота, для здоровья человека. Несмотря на отсутствие убедительных доказательств того, что BLV патогенен для человека, обеспокоенность по поводу этиологической роли этого вируса в возникновении онкологических заболеваний у людей требует продолжения научных исследований и усиления борьбы с этим инфекционным ретровирусным пролиферативным заболеванием, распространенным в скотоводческих хозяйствах.

\footnotetext{
1Российская академия наук,

119991 Россия, г. Москва, Ленинский просп., 14, e-mail: ktqrjp7@yandex.ru $\bowtie$;

2 ФГБНУ Федеральный научный иентр -

Всероссийский НИИ экспериментальной ветеринарии

им. К.И. Скрябина и Я.Р. Коваленко,

109428 Россия, г. Москва, Рязанский просп., 24, к. 1,

e-mail: admin@viev.ru;

${ }^{3}$ Национальный научный иентр

Институт экспериментальной и клинической

ветеринарной медицины НААН Украины,

61023 Украина, г. Харьков, улица Пушкинская, 83,

e-mail: inform@vet.kharkov.ua;

${ }^{4}$ ФГБОУ ВО Белгородский государственный

аграрный университет им. В.Я. Горина,

308503 Россия, Белгородская обл., Белгородский р-н,

пос. Майский, ул. Вавилова, 1,

e-mail: mycobacteria@rambler.ru
}

Sel'skokhozyaistvennaya biologiya [Agricultural Biology], 2021, V. 56, № 2, pp. 230-244

Поступила в редакцию 4 февраля 2020 года

\title{
Bovine leukemia virus INFECTION - DIAGNOSTICS, ERADICATION, AND ANTHROPOZOONOTIC POTENTIAL (BACKGROUND) (review)
}

\author{
I.M. Donnik ${ }^{1}$, M.I. Gulyukin ${ }^{2}$, V.A. Busol ${ }^{3}$, L.V. Kovalenko ${ }^{3}$, A.M. Kovalenko $^{4}$
}

${ }^{1}$ Russian Academy of Sciences, 14, Leninskii prosp., Moscow, 119991 Russia, e-mail ktqrjp7@yandex.ru ( $₫$ corresponding author); 
${ }^{2}$ Federal Scientific Center - Skryabin and Kovalenko All-Russian Research Institute of Experimental Veterinary Medicine, 24/1, Ryazanskii prosp., Moscow, 109428 Russia, e-mail admin@viev.ru;

${ }^{3}$ National Scientific Center Institute of Experimental and Clinical Veterinary Medicine of the National Academy of Agricultural Sciences of Ukraine, 83, Pushkinskaya Street, Kharkov, 61023 Ukraine, e-mail inform@vet.kharkov.ua;

${ }^{4}$ Gorin Belgorod State Agricultural University, 1, ul. Vavilova, Belgorod District, Belgorod Province, pos. Maiskii, 308503 Russia, e-mail: mycobacteria@rambler.ru

ORCID:

Donnik I.M. orcid.org/0000-0002-8593-7470

Gulyukin M.I. orcid.org/0000-0002-7489-6175

The authors declare no conflict of interests

Received February 4, 2020

Busol V.A. orcid.org/0000-0002-9618-0493

Kovalenko A.M. orcid.org/0000-0002-7219-4049

doi: 10.15389/agrobiology.2021.2.230eng

\section{Abstract}

Of tumor diseases in the global animal husbandry industry, the greatest danger is bovine leukemia. Since the last century, this neoplastic disease has remained relevant for veterinary medicine and, in addition, more and more questions arise concerning the potential threat of the Bovine leukemia virus (BLV) for humans. The problem is being discussed (G.Yu. Kosovskiy et al., 2016) which additionally stimulates both fundamental research of the pathogen and the pathology, as well as the methods for detection to improve dairy cattle breeding and veterinary safety. A number of publications are devoted to BLV prevalence, peculiarities, the prospects for improving animal health and welfare based on selection and vaccines developed in the world (S.G. Hopkins et al., 1997; M.A. Juliarena et al., 2017). In our report, we retrospectively compare the experience of BLV eradication in the USSR, Russia and abroad, additionally focusing on the possible role of this pathogen in the occurrence of cancer in humans. In veterinary practice, serological tests, i.e., immunodiffusion (ID) assay in agar gel and enzyme-linked immunosorbent assay (ELISA) are mostly used to detect the BLV infection. G.C. Buehring et al. (2019) reported the detection of BLV proviral DNA in blood leukocytes in $38 \%$ of patients examined by PCR and DNA sequencing. IgG antibodies to BLV were detected in $32 \%$, IgM - in $58 \%$, and IgA - in $32 \%$ of the samples tested. Accumulated data indicate metabolic changes in the BLV-positive animals, e.g., disorder in the metabolism of tryptophan, a critical essential acid, leading to the accumulation of dangerous endogenous metabolites in the body. Particularly, free tryptophan, indole and anthranilic acid increased in level 4-8-fold are deposited in the organs of the immune and hematopoietic system (lymph nodes, spleen, liver), in the mammary gland, lungs, and kidneys. It has been established that the milk of leukemic animals differs from the milk of healthy cows in terms of physicochemical, bacteriological (lysozyme), technological parameters and mineral composition. In C57 mice fed with pasteurized milk and heat-treated meat from ID-positive cows, the blood cell profile changed. Available data drive to the unambiguous conclusion that the products derived from BLV-infected cattle pose an increased risk to humans. Despite the lack of convincing evidence of the BLV pathogenicity for humans, concerns about the etiological role of this virus in the occurance of cancer in humans additionally necessitates continuing research on the control and eradication of this common oncogenic retro-virus in livestock farms.

Keywords: leukemia, Bovine leukemia virus, proviral DNA, PCR indication, IgA, IgM, IgG, blood cells, endogenous metabolites, milk, vaccination, eradication.

\section{REFERENCES}

1. Gutiérrez G., Rodríguez S.M., de Brogniez A., Gillet N., Golime R., Burny A., Jaworski J.P., Alvarez I., Vagnoni L., Trono K., Willems L. Vaccination against $\delta$-retroviruses: the bovine leukemia virus paradigm. Viruses, 2014, 6(6): 2416-2427 (doi: 10.3390/v6062416).

2. Kozyreva N.G., Ivanova L.A., Stepanova T.V., Gulyukin M.I. Dostizheniya nauki i tekhniki APK, 2014, 1: 47-51 (in Russ.).

3. Mandigra M.S. Spriinyatlivist' tvarin riznikh vidiv do virusu leikozu velikoï rogatoï khudobi. Visnik BTSDAU (Bila TSerkva), 1998, 7(1): 52-54 (in Ukr.).

4. Ma J.-G., Zheng W.-B., Zhou D.-H., Qin S.-Y., Yin M.-Y., Zhu X.-Q., Hu G.-X. First report of bovine leukemia virus infection in yaks (Bos mutus) in China. BioMed Research International, 2016, 2016: Article ID 9170167 (doi: 10.1155/2016/9170167).

5. Stepanova T.V. RJOAS, 2016, 8(56): 49-56 (doi: 10.18551/rjoas.2016-08.08) (in Russ.).

6. Smirnov P.N., Bateneva N.V. Dostizheniya nauki i tekhniki APK, 2012, 4: 71-72 (in Russ.).

7. Rhodes J.K., Pelzer K.D., Johnson Y.J. Economic implications of bovine leukemia virus infection in mid-Atlantic dairy herds. Journal of the American Veterinary Medical Association, 2003, 223(3): 346-352 (doi: 10.2460/javma.2003.223.346).

8. OIE. Manual of diagnostic tests and vaccines for terrestrial animals: chapter 2.4.11. Enzootic bovine leukosis. World organization for animal health, 2012.

9. Doronin N.N., Busol V.A., Subaev G.Kh. Leikoz krupnogo rogatogo skota [Bovine leukemia]. Kiev, 1976 (in Russ.).

10. Mishchenko V.A., Petrova O.N., Karaulov A.K., Mishchenko A.V. Problema leikoza krupnogo 
rogatogo skota [Bovine leukemia problem]. Vladimir, 2018 (in Russ.).

11. Kozyreva N.G., Gulyukin M.I. Veterinariya Kubani, 2017, 6: 4-9 (in Russ.).

12. Sagata N.T., YasunagaJ., Tsuziiku-KawnmurnK., OhishiY., Ogawa Y. Complete nucleotide sequence of the genome of bovine leukemia virus: its evolutionary relationship to other retro-viruses. PNAS USA, 1985, 82: 677-681 (doi: 10.1073/pnas.82.3.677).

13. Khoury J.D., Tannir N.M., Williams M.D., Chen Y., Yao H., Zhang J., Thompson E.J., TCGA Network, Meric-Bernstam F., Medeiros L.J., Weinstein J.N., Su X. Landscape of DNA virus associations across human malignant cancers: analysis of 3,775 cases using RNA-Seq. Journal of Virology, 2013, 87(16): 8916-8926 (doi: 10.1128/JVI.00340-13).

14. Parfanovich M.I., Busol V.A. Ezhegodnik nauchnykh issledovanii po veterinarii, 1978, 9: 781-796 (in Russ.).

15. Olaya-Galán N.N., Corredor-Figueroa A.P., Guzmán-Garzón T.C., Ríos-Hernandez K.S., SalasCárdenas S.P., Patarroyo M.A., Gutierrez M.F. Bovine leukaemia virus DNA in fresh milk and raw beef for human consumption. Epidemiol. Infect., 2017, 145(15): 3125-3130 (doi: $10.1017 /$ S0950268817002229).

16. Zhang R., Jiang J., Sun W. Lack of association between bovine leukemia virus and breast cancer in Chinese patients. Breast Cancer Res., 2016, 18(1): 101 (doi: 10.1186/s13058-016-0763-8).

17. Gao A., Kouznetsova V.L., Tsigelny I.F. Bovine leukemia virus relation to human breast cancer: meta-analysis. Microb. Pathog., 2020, 2020: 104417 (doi: 10.1016/j.micpath.2020.104417).

18. Leisering A. Hypertrophy der Malpighischen Körperoen der Milz. Berl. Vet. West. Kgr. Sachsen, 1871, 16: 15-16.

19. Olson C., Miller J. History and terminology of enzootic bovine leukosis. In: Enzootic bovine leukosis and Bovine leukemia virus /A. Burny, M. Mammerickx (eds.). Martinus Nijhoff Publishing, Boston, MA, USA, 1987: 3-14.

20. Yarchuk B.M., Tirsin R.V., Dovgal' O.V., Bilik S.A. Kompleksnii metod ozdorovlennya velikoï rogatoï khudobi vid leikozu v gospodarstvakh Ukraïni. Naukovii visnik veterinarnoï meditsini, 2014, 14(114): 105-110 (in Ukr.).

21. Gutiérrez G., Rodríguez S.M., Vilor A., Gillet N., De Brogniez A., Trono K., Willems L. An efficient vaccine against bovine leukemia virus. Retrovirology, 2015, 12: R3 (doi: 10.1186/17424690-12-S1-P3).

22. Aida Y., Murakami H., Takahashi M., Takeshima S.N. Mechanisms of pathogenesis induced by bovine leukemia virus as a model for human T-cell leukemia virus. Frontiers in Microbiology, 2013, 4: 328 (doi: 10.3389/fmicb.2013.00328).

23. Bendixen H.J. Bovine enzootic leukosis. Adv. Vet. Sci., 1965, 10: 129-204

24. Ferrer J.F. Bovine lymphosarcoma. Adv. Vet. Sci. Comp. Med., 1980, 24: 1-68.

25. Apal'kin V.A., Gulyukin M.I., Petrov N.I. Leikoz krupnogo rogatogo skota [Bovine leukemia]. St. Petersburg, 2005 (in Russ.).

26. Busol V.A. Leikoz sel'skokhozyaistvennykh zhivotnykh [Leukemia of farm animals]. Kiev, 1988 (in Russ.).

27. Krasnikova E.S. Larionova O.S. Vestnik veterinarii, 2014, 2(69): 85-87 (in Russ.).

28. Hopkins S.G., DiGiacomo R.F. Natural transmission of bovine leukemia virus in dairy and beef cattle. Vet. Clin. North Am. Food Anim. Pract., 1997, 13(1): 107-128 (doi: 10.1016/s07490720(15)30367-4).

29. Gulyukin M.I., Kozyreva N.G., Ivanova L.A., Stepanova T.V., Klimenko A.I., Kovalenko A.V., Drobin YU.D., Vasilenko V.N. Voprosy virusologii, 2015, 60(5): 32-37 (in Russ.).

30. Kudryavtseva T.P. Leikoz zhivotnykh [Animal leukemia]. Moscow, 1980 (in Russ.).

31. Burba L.G. Valikhov A.F., Gorbatov V.A. Leikozy i zlokachestvennye opukholi zhivotnykh [Leukemias and malignant tumors of animals]. Moscow, 1988 (in Russ.).

32. Miller J.M., Olson C. Precipitating antibody to an internal antigen of the C-type virus associated with bovine lymphosarcoma. Journal of the National Cancer Institute, 1972, 249: 1459-1462.

33. Zaviryukha A.İ., Zviryukha G.A. Novii efektivnii sposib ozdorovlennya velikoï rogatoï khudobi, vrazhenoï virusom leikozu. Naukovii visnik LNUVMBT imeni S.Z. Gzhits'kogo, 2011, 40(45): 141147 (in Ukr.).

34. Berzyak A.G., Kovalyuchko V.S., Grotevich V.S., Kirichuk L.I. Veterinariya, 1990, 12: 13-15 (in Russ.).

35. Ivanova L.A. Byul. VIEV, 1999, 72: 202-209 (in Russ.).

36. Timoshina S.V., Badaeva O.B. Veterinariya i kormlenie, 2012, 4: 6-7 (in Russ.).

37. Zandomeni R.O., Carrera-Zandomeni M., Esteban E., Ferrer J.F. The trans-activating C-type retroviruses share a distinct epitope(s) that induces antibodies in certain infected hosts. J. Gen. Virol., 1991, 72(9): 2113-2119 (doi: 10.1099/0022-1317-72-9-2113).

38. Burridge M.J. The zoonotic potential of bovine leukemia virus. Veterinary Research Communications, 1981, 5(1): 117-126 (doi: 10.1007/BF02214976).

39. Donnik I.M., Petropavlovskii M.V. Veterinariya Kubani, 2010, 3: 12-13 (in Russ.).

40. Ballagi-Pordany A., Klintevall K., Merza M., Klingeborn B., Belak S. Direct detection of bovine leukemia virus infection: practical applicability of a double polymerase chain reaction. Zentralbl. Veterinarmed. B, 1992, 39(1): 69-77 (doi: 10.1111/j.1439-0450.1992.tb01140.x). 
41. Klintevall K., Ballagi-Pordány A., Näslund K., Belák S. Bovine leukaemia virus: rapid detection of proviral DNA by nested PCR in blood and organs of experimentally infected calves. Veterinary Microbiology, 1994, 42(2-3): 191-204 (doi: 10.1016/0378-1135(94)90018-3).

42. El Daous H., Mitoma S., Elhanafy E., Thi Nguyen H., Thi Mai N., Hara A., Duangtathip K., Takezaki Y., Kaneko C., Norimine J., Sekiguchi S. Establishment of a novel diagnostic test for Bovine leukaemia virus infection using direct filter PCR. Transbound Emerg. Dis., 2020, 67(4): 1671-1676 (doi: 10.1111/tbed.13506).

43. Donnik I.M., Petropavlovskii M.V. Veterinariya Kubani, 2015, 4: 8-10 (in Russ.).

44. Dus Santos M.J., Trono K., Lager I., Wigdorovitz A. Development of a PCR to diagnose BLV genome in frozen semen samples. Veterinary Microbiology, 2007, 119(1): 10-18 (doi: 10.1016/j.vetmic.2006.08.030).

45. Kuckleburg C.J., Chase C.C., Nelson E.A., Marras S.A., Dammen M.A., Christopher-Hennings J. Detection of bovine leukemia virus in blood and milk by nested and real-time polymerase chain reactions. J. Vet. Diagn. Invest., 2003, 15(1): 72-76 (doi: 10.1177/104063870301500117).

46. Rodríguez S.M., Florins A., Gillet N., de Brogniez A., Sánchez-Alcaraz M.T., Boxus M., Boulanger F., Gutiérrez G., Trono K., Alvarez I., Vagnoni L., Willems L. Preventive and therapeutic strategies for bovine leukemia virus: lessons for HTLV. Viruses, 2011, 3(7): 1210-1248 (doi: $10.3390 / \mathrm{v} 3071210)$.

47. DiGiacomo R.F. The epidemiology and control of bovine leukemia virus infection. Veterinary Medicine, 1992, 87: 248-257.

48. Johnson R., Gibson C.D., Kaneene J.B. Bovine leukemia virus: a herd-based control strategy. Preventive Veterinary Medicine, 1985, 3(4): 339-349 (doi: 10.1016/0167-5877(85)90011-X).

49. Kaja R.W., Olson C., Rowe R.F., Stauffacher R.H., Strozinski L.L., Hardie A.R., Bause I. Establishment of a bovine leukosis virus-free dairy herd. J. Am. Vet. Med. Assoc., 1984, 184(2): 184-185.

50. Shettigara P.T., Samagh B.S., Lobinowich E.M. Control of bovine leukemia virus infection in dairy herds by agar gel immunodiffusion test and segregation of reactors. Canadian journal of veterinary research $=$ Revue canadienne de recherche veterinaire. $1989,53(1)$ : 108-110.

51. Gulyukin M.I., Simonyan G.A., Shishkin A.V., Zueva E.V., Barabanov I.I., Azhirkina N.A. Veterinarnyi konsul'tant, 2004, 18: 4-5 (in Russ.).

52. Prosvirnin G.S., Kuz'min V.A., Gulyukin M.I., Fogel' L.S., Kozyrenko O.V., Krotov L.N., Mizernyi S.B., Zubova T.V., Smolovskaya O.V., Pleshkov V.A. Algoritm primeneniya GIS v epizootologicheskom monitoringe leikoza krupnogo rogatogo skota $v$ Leningradskoi i Kemerovskoi oblastyakh: metodicheskie rekomendatsii [Algorithm for the use of GIS in epizootic monitoring of cattle leukemia in the Leningrad and Kemerovo regions: guidelines]. St. Petersburg, 2019 (in Russ.).

53. Donnik I.M., SHkuratova I.A., Tatarchuk A.T. Voprosy normativno-pravovogo regulirovaniya $v$ veterinarii, 2015, 2: 42-46 (in Russ.).

54. Kuznetsova N.V., Kuznetsov N.V., Simonyan G.A. Veterinariya, 1997, 5: 12-15 (in Russ.).

55. Simonyan G.A. Farm Animals, 2016, 1(11): 26-28 (in Russ.).

56. Sulimova G.E., Udina I.G., Shaikhaev G.O., Zakharov I.A. Genetika, 1995, 31(9): 1294-1299 (in Russ.).

57. Gulyukin M.I., Ivanova L.A., Kozyreva N.G. Materialy nauchno-prakticheskoi konferentsii «Realizatsiya dostizhenii veterinarnoi nauki dlya obespecheniya veterinarnogo, sanitarnogo $i$ epizooticheskogo blagopoluchiya zhivotnovodstva Bryanskoi oblasti v sovremennykh usloviyakh» [Proc. Int. Conf. «Implementation of the achievements of veterinary science to ensure the veterinary, sanitary and epizootic welfare of animal husbandry in the conditions of Bryansk region»]. Bryansk, 2015: 78-89 (in Russ.).

58. Valikhov A.F. Molochnaya promyshlennost', 2018, 9: 74-77 (in Russ.).

59. Krivonogova A.S. Teoreticheskoe obosnovanie $i$ razrabotka sistemy polucheniya kachestvennoi produktsii molochnogo zhivotnovodstva $v$ regione s kombinirovannym tekhnogennym zagryazneniem. Avtoreferat doktorskoi dissertatsii [Theoretical substantiation and development of system for obtaining high-quality dairy products in a region with combined technogenic pollution. DSc Thesis]. Moscow, 2017 (in Russ.).

60. Donnik I.M., Shilova E.N., Shilov V.B. Vestnik Altaiskogo gosudarstvennogo agrarnogo universiteta, 2006, 5(25): 37-39 (in Russ.).

61. Busol V.A. Materialy $k$ izucheniyu epizootologii leikoza krupnogo rogatogo skota v Ukrainskoi SSR. Avtoreferat kandidatskoi dissertatsii [Materials for study of cattle leukemia epizootology in the Ukrainian SSR. PhD Thesis]. Belaya TSerkov', 1969 (in Russ.).

62. Busol L.V., Kovalenko L.V., Tons'ka T.G. Sbornik trudov SWorld, Materialy Mezhdunarodnoi nauchno-prakticheskoi konferentsii «Sovremennye napravleniya teoreticheskikh i prikladnykh issledovanii-2012» [Proc. Int. Conf. «Modern directions of theoretical and applied research-2012»]. Odessa, 2012, 1(30): 11-15 (in Russ.).

63. Korniienko L.Y., Pyskun A.V., Tsarenko T.M., Ukhovskyi V.V., Kyivska G.V., Moroz O.A., Kovalenko V.L., Aliekseieva G.B. Retrospective analysis of the epizootic situation of enzootic bovine leukosis in Ukraine in 1994-2019. Regulatory Mechanisms in Biosystems, 2020, 11(3): 372377 (doi: 10.15421/022057). 
64. Busol V.O. Ukraïns'ka naukova shkola veterinarnoï leikozologiï: stanovlennya, rozvitok, maibutn€. Veterinarna meditsina, 2018, 104: 92-102 (in Ukr.).

65. Busol V.A., Dostoevskii P.P., Karpenko N.A., Mandygra N.S., Matuzenko V.A. Tez. dokl. Mezhdunar. nauch.-proizvod. konf. "Sovremennye dostizheniya $v$ bor'be $i$ profilaktike leikoza krupnogo rogatogo skota» [Proc. Int. Conf. «Modern advances in the fight and prevention of bovine leukemia»]. Kishinev, 1994: 37 (in Russ.).

66. Tons'ka T.G. Rozrobka imunogennikh preparativ ta sistemi ïkh vikoristannya dlya profilaktiki leikozu velikoï rogatoï khudobi (eksperimental'ni doslidzhennya). Avtoref. kand. dis. Kï̈v, 2012 (in Ukr.).

67. Gorbatenko S.K., SHapovalova O.V., Korn€ikov O.M., Zdan€vich P.P., Persheguba F.F., Lum'yanik S.V., Prisyazhnyuk İ.V. Napryamki zapobigannya retsidivu epizootiï leikozu velikoï rogatoï khudobi. Veterinarna meditsina, 2014, 98: 84-87 (in Ukr.).

68. Stegnii B.T., SHapovalova O.V., Gorbatenko S.K., Korneikov A.N., Gorzheev V.M. Veterinarna meditsina, 2013, 97: 242-255.

69. Rusinovich A.A. Leikoz krupnogo rogatogo skota. Epizootologiya, mery bor'by i profilaktiki [Bovine leukemia. Epizootology, control and prevention measures]. Minsk, 2000 (in Russ.).

70. Rusinovich A.A. Izvestiya Natsional'noi akademii nauk Belarusi. Seriya agrarnykh nauk, 2002, 2: 73-77 (in Russ.).

71. Malaya E.O., Piontkovskii V.I. GISAP: Biology, Veterinary Medicine And Agricultural Sciences, 2013, 1: 44-46 (in Russ.).

72. Smailova B.T., Baigazanov A.N. Materialy XVI Mezhdunarodnoi nauchno-prakticheskoi konferentsii «Perspektivy razvitiya nauki v sovremennom mire» [Proc. XVI Int. Conf. «Prospects for development of science in the modern world»]. Ufa, 2019: 16-27 (in Russ.).

73. Bakhtakhunov Yu.Kh., Baramova Sh.A., Aitlesova R.B. Vestnik sel'skokhozyaistvennoi nauki Kazakhstana, 2011, 12: 25-55 (in Russ.).

74. Bakhtakhunov Yu.Kh., Baramova Sh.A. Sbornik nauchnykh trudov KazNIVI, 2011, LVII: 98-100 (in Russ.).

75. Markson L.M., Roberts D.H., Bradley R. Studies on bovine leukosis as it is seen in England and Wales. Annals of Veterinary Research, 1978, 9(4): 899-902.

76. Odend'hal S. Bovine leukosis: an example of poor disease monitoring of international livestock shipments to developing countries. Soc. Sci. Med., 1986, 23(10): 1017-1020 (doi: 10.1016/02779536(86)90259-5).

77. European Commission. Bovine and swine diseases. 2014 Annual report. Available: https://ec.europa.eu/food/sites/food/files/animals/docs/la_bovine_final_report_2014.pdf. Accessed: 05.12 .2018

78. LaDronka, R.M., Ainsworth S., Wilkins M.J., Norby B., Byrem T.M., Bartlett P.C. Prevalence of bovine leukemia virus antibodies in US dairy cattle. Veterinary Medicine International, 2018, 2018: 5831278 (doi: 10.1155/2018/5831278).

79. VanLeeuwen J.A., Keefe G.P., Tremblay R., Power C., Wichtel J.J. Seroprevalence of infection with Mycobacterium avium subspecies paratuberculosis, bovine leukemia virus, and bovine viral diarrhea virus in maritime Canada dairy cattle. Can. Vet. J., 2001, 42(3): 193-198.

80. VanLeeuwen J.A., Forsythe L., Tiwari A., Chartier R. Seroprevalence of antibodies against bovine leukemia virus, bovine viral diarrhea virus, Mycobacterium avium subspecies paratuberculosis, and Neospora caninum in dairy cattle in Saskatchewan. Can. Vet. J., 2005, 46(1): 56-58.

81. Nekouei O.A. Study of prevalence, risk factors, and lifetime impacts of infection with bovine leukemia virus in the Canadian dairy industry. University of Prince Edward Island, 2015.

82. Polat M., Takeshima S.N., Aida Y. Epidemiology and genetic diversity of bovine leukemia virus. Virology Journal, 2017, 14(1): 209 (doi: 10.1186/s12985-017-0876-4).

83. OIE. Kodeks zdorov'ya nazemnykh zhivotnykh MEB [OIE Terrestrial animal health code]. World Organization for Animal Health, France, 2019 (in Russ.).

84. Onuma M., Hodatsu T., Yamamoto S., Higashihara M., Masu S., Mikami T., Izawa H. Protection by vaccination against bovine leukemia virus infection in sheep. Am. J. Vet. Res., 1984, 45(6): 1212-1215.

85. Usui T., Konnai S., Tajima S., Watarai S., Aida Y., Ohashi K., Onuma M. Protective effects of vaccination with bovine leukemia virus (BLV) Tax DNA against BLV infection in sheep. Journal of Veterinary Medical Science, 2003, 65(11): 1201-1205 (doi: 10.1292/jvms.65.1201).

86. Busol V.A., Mandryga N.S., Byaletskii N.S. Materialy Mezhdunarodnoi nauchnoi konferentsii «Obshchaya epizootologiya: immunologiya, ekologiya i metodologicheskie problemy» (Khar'kov, 20-22 sentyabrya 1995 goda) [Proc. Int. Conf. «General epizootology: immunology, ecology and methodological problems» (Kharkov, September 20-22, 1995)]. Khar'kov, 1995: 217-220 (in Russ.).

87. McClure H.M., Keeling M.E., Custer R.P., Marshak R.R., Abt D.A., Ferrer J.F. Erythroleukemia in two infant chimpanzees fed milk from cows naturally infected with the bovine C-type virus. Cancer Res., 1974, 34(10): 2745-2757.

88. Shabeykin A.A., Gulyukin A.M., Stepanova T.V., Kozyreva N.G., Ivanov L.A. Risk assessment for interspecies transmission of enzootic bovine leukemia. IOP Conference Series: Earth and Environmental Science, 2019, 315(4): 042036. 
89. Buehring G.C., Shen H., Schwartz D.A., Lawson J.S. Bovine leukemia virus linked to breast cancer in Australian women and identified before breast cancer development. PLoS ONE, 2017, 12(6): e0179367 (doi: 10.1371/journal.pone.0179367).

90. Buehring G.C., DeLaney A., Shen H., Chu D.L., Razavian N., Schwartz D.A., Demkovich Z.R., Bates M.N. Bovine leukemia virus discovered in human blood. BMC Infect Dis., 2019, 19(1): 297 (doi: 10.1186/s12879-019-3891-9).

91. Bender A.P., Robison L.L., Kashmiri S.V., McClain K.L., Woods W.G., Smithson W.A., Heyn R., Finlay J., Schuman L.M., Renier C. No involvement of bovine leukemia virus in childhood acute lymphoblastic leukemia and non-Hodgkin's lymphoma. Cancer Res., 1988, 48(10): 2919-2922.

92. Lee J., Kim Y., Kang C.S., Cho D.H., Shin D.H., Yum Y.N., Oh J.H., Kim S.H., Hwang M.S., Lim C.J., Yang K.H., Han K. Investigation of the bovine leukemia virus proviral DNA in human leukemias and lung cancers in Korea. J. Korean Med. Sci., 2005, 20(4): 603-606 (doi: 10.3346/jkms.2005.20.4.603).

93. Buehring G.C., Philpott S.M., Choi K.Y. Humans have antibodies reactive with Bovine leukemia virus. AIDS Res. Hum. Retroviruses, 2003, 19(12): 1105-1113 (doi: 10.1089/088922203771881202).

94. Gillet N.A., Willems L. Whole genome sequencing of 51 breast cancers reveals that tumors are devoid of bovine leukemia virus DNA. Retrovirology, 2016, 13: 75 (doi: 10.1186/s12977-0160308-3).

95. Klimov N.M., Koromyslova G.L. Byull. VIEV, 1974, 17: 50-51 (in Russ.).

96. YAkubchak O., Taran T., Bilik R. Zmini leikotsitiv krovi doslidnikh mishei pri zgodovuvanni ïm moloka ta m'yasa, otrimanikh vid RIDD-pozitivnikh na leikoz koriv. Veterinarna meditsina Ukrä̈i, 2008, 1: 16-18 (in Ukr.).

97. Kornelaeva R.P., Pavlova E.V. Veterinariya sel'skokhozyaistvennykh zhivotnykh, 2006, 7: 68 -69 (in Russ.).

98. Juliarena M.A., Barrios C.N., Lützelschwab C.M., Esteban E.N., Gutiérrez S.E. Bovine leukemia virus: current perspectives. Virus Adaptation and Treatment, 2017, 9: 13-26 (doi: 10.2147/VAAT.S113947). 